\title{
Rapid and Efficient Colony-PCR for High Throughput Screening of Genetically Transformed Chlamydomonas reinhardtii
}

\author{
Serge Basile Nouemssi ${ }^{1}{ }^{1}$, Manel Ghribi ${ }^{1}$, Rémy Beauchemin ${ }^{1}$, Fatma Meddeb-Mouelhi ${ }^{1,2}$, \\ Hugo Germain ${ }^{1,2}$ and Isabel Desgagné-Penix ${ }^{1,2, *(\mathbb{D})}$ \\ 1 Department of Chemistry, Biochemistry and Physics, Université du Québec à Trois-Rivières, 3351, \\ boul. des Forges, C.P. 500, Trois-Rivières, QC G9A 5H7, Canada; serge.nouemssi@uqtr.ca (S.B.N.); \\ Manel.Ghribi@uqtr.ca (M.G.); Remy.Beauchemin@uqtr.ca (R.B.); Fatma.Meddeb@uqtr.ca (F.M.-M.); \\ Hugo.Germain@uqtr.ca (H.G.) \\ 2 Groupe de Recherche en Biologie Végétale, Université du Québec à Trois-Rivières, 3351, boul. des Forges, \\ C.P. 500, Trois-Rivières, QC G9A 5H7, Canada \\ * Correspondence: Isabel.Desgagne-Penix@uqtr.ca
}

Received: 21 July 2020; Accepted: 8 September 2020; Published: 10 September 2020

\begin{abstract}
Microalgae biotechnologies are rapidly developing into new commercial settings. Several high value products already exist on the market, and biotechnological development is focused on genetic engineering of microalgae to open up future economic opportunities for food, fuel and pharmacological production. Colony-polymerase chain reaction (colony-PCR or CPCR) is a critical method for screening genetically transformed microalgae cells. However, the ability to rapidly screen thousands of transformants using the current colony-PCR method, becomes a very laborious and time-consuming process. Herein, the non-homologous transformation of Chlamydomonas reinhardtii using the electroporation and glass beads methods generated more than seven thousand transformants. In order to manage this impressive number of clones efficiently, we developed a high-throughput screening (HTS) CPCR method to rapidly maximize the detection and selection of positively transformed clones. For this, we optimized the Chlamydomonas transformed cell layout on the culture media to improve genomic DNA extraction and cPCR in 96-well plate. The application of this optimized HTS CPCR method offers a rapid, less expensive and reliable method for the detection and selection of microalgae transformants. Our method, which saves up to $80 \%$ of the experimental time, holds promise for evaluating genetically transformed cells and selection for microalgae-based biotechnological applications such as synthetic biology and metabolic engineering.
\end{abstract}

Keywords: high-throughput screening; microalgae; colony-PCR method; genetic transformation; Chlamydomonas reinhardtii; synthetic biology

\section{Introduction}

Chlamydomonas reinhardtii is a common single-celled photosynthetic microalga, populating fresh water and moist soil. It is also known for easy isolation, cultivation, and transformation [1,2]. This unicellular, eukaryotic, green microalga strain has a well-characterized genome [3] and it has been commonly used to study a number of biological processes, which makes it a model organism for biotechnological studies. C. reinhardtii has been widely used in basic and applied sciences and it is considered an ideal host and cell-factory for the production of high-added value bioproducts [4-6]. In addition, because of its rapid growth and high biomass production at low cost, $C$. reinhardtii has attracted the interest of several biotechnologists. Nevertheless, the transformation and selection remain the decisive stages in using C. reinhardtii microalgae as a biotechnological platform [7]. Several genetic 
transformation methods have been established to introduce foreign DNA fragments into the C. reinhardtii including electroporation, glass beads, silicon carbide whiskers, microparticle bombardment and Agrobacterium-mediated transformation [8-11]. However, the integration of exogenous DNA into the nuclear genome predominantly occurs randomly via Non-Homologous-End-Joining (NHEJ), leading to a large and heterogeneous population of transformed cells (tens of thousands) with varied expression levels. Moreover, the integrated foreign genes or cassettes may be subjected to deletions, genomic rearrangements and insertions of short DNA fragments [12,13], in addition to the epigenetic silencing phenomenon that decrease or suppress the expression of the transgenes. Such events require a meticulous high throughput screening (HTS) technique to handle the high number of the genetically transformed cells with desirable expression level [8,14-17].

The traditional method of initial screening of microalgae transformants is based on selectable markers such as antibiotic resistance and fluorescence, that are commonly used or a combination of bicistronic mRNA constructs that allows expression of a gene of interest (GOI) and a selectable marker [7,18-30]. However, the screening method based on antibiotic resistance approach remains limited due to its large number of false positives. On other hand, fluorescence reporter screening has been used in several studies and has demonstrated a high potential in order to select positively transformed microalgae based on their fluorescence emission [21,26-29]. This method seems, however, inconvenient for laboratories indisposed of the fluorescent agar plate reader. Additionally, strains with low fluorescence could not be easily detected. An additional screening method, named colony polymerase chain reaction (cPCR) is used to select antibiotic-resistant transformants that harbor copies of the integrated expression cassettes [31]. Although DNA purification is still used, the Chelex method seems to be way easier and faster. $\mathrm{CPCR}$ using Chelex for DNA extraction is a powerful technique that bypasses DNA purification [31]. This method relies on the selectivity of PCR amplification to determine whether a microorganism of interest integrates the target inserted DNA. For bacteria and yeast, simply adding a small portion of cell colony directly to a PCR master mix will introduce enough template DNA for amplification [32]. cPCR is challenging with microalgae because of their complex cell wall structure that precludes efficient extraction of their genetic material leading to a more laborious and time-consuming PCR, especially when the number of transformants to be screened is large. Another challenging issue is to maintain thousands of clones by subculturing and managing them using single Eppendorf and PCR tubes for the processing of transformants by CPCR. Hence, the need to develop an optimized high throughput screening (HTS) cPCR method, to maximize the detection and selection of hundreds or even thousands of positive transformed clones rapidly, becomes an urgent requirement. Therefore, the efficiency is critical: every improvement in workflow efficiency leads to significant savings in time. Eliminating pipetting steps reduces the potential for contamination and error, and minimizes repetitive strain-induced injury. Simplifying the screening procedure also enables better standardization between different laboratory personnel, which can be crucial for screening a huge number of transformants.

Here, we report a rapid and an optimized method for handling a high number of C. reinhardtii transformants with embedded foreign genes or cassettes in the genomic DNA. We describe details (steps and time savings) of this rapid and specific molecular technique and high-throughput (HT) PCR samples loading onto agarose gel for electrophoresis and the analysis of a high number of genetically transformed microalgae. The effectiveness of the proposed procedure, 96-well plate PCR (named here, $\mathrm{HT}$ ), was compared with single tube PCR (named here, standard (ST)) screening.

\section{Materials and Methods}

\subsection{C. reinhardtii Strain, Plasmid and Primers Design}

C. reinhardtii strain C-137 wild type (wt) and the pOptimized_mRuby2_Hygromycin (pOpt_mRuby2_Hyg) [21] cloning vector were purchased from the Chlamydomonas Resource Center (Minneapolis, MN, USA) [33]. Recombinant plasmid construct, pOpt_mRuby2_Hyg containing gene 
of interest (GOI) (Appendix A Figure A1) was made using Gibson assembly strategy. Transformed E. coli DH5 alpha cells, bearing the pOpt_mRuby2_Hyg-GOI expression, were selected on LB-agar with $100 \mu \mathrm{g} / \mathrm{mL}$ Ampicillin. Plasmid DNA was isolated using a Biobasic plasmid extraction kit (Cat no\# BS614). Plasmid DNA was then used to ascertain the integrity of the nucleotide sequence by next gene sequencing (at MGH CCIB DNA CORE). The nuclear phosphoglycerate kinase (PGK), a housekeeping gene [34] (GeneBank ID: AF244144.1), is used as a positive PCR control. The oligonucleotide primers used in this study were synthesized by Integrated DNA Technologies (San Diego, CA, USA) [35]. The following primers were used to amplify nuclear (Nuc) PGK and GOI genes to obtain PCR product of 944 and $506 \mathrm{bp}$, respectively:

Nuc_PGK_F: 5'AGTCCGAACAACCCACTTAC 3';

Nuc_PGK_R: 5' CAGAGCTCAGGAGGTGAAATAG 3';

GOI_F: 5' GCTGGGCATCAAGAAGACCG 3';

GOI_R: 5' CCTGCGTGTAGTTGTTCGGG 3.'

\subsection{C. reinhardtii Growth and Transformation Conditions}

Unless otherwise stated, cells were cultivated mixotrophically at $25^{\circ} \mathrm{C}$ in tris-acetate phosphate (TAP) medium under moderate and continuous white fluorescent light at the intensity of $50 \mu \mathrm{mol}$ photons $\mathrm{m}^{-2} \mathrm{~s}^{-1}$ in shake flasks or on agar plates with a relative humidity ( $\mathrm{Rh}$ ) of $50 \%$.

Herein, electroporation method was performed for transformation as described in $[10,36,37]$ with slight modification. C. reinhardtii cells were transformed using the Bio-Rad Genepulser XcellTM electroporation machine and $4 \mathrm{~mm}$ cuvette under the following parameters: voltage $0.5 \mathrm{kV}$; capacitance $50 \mu \mathrm{F}$; resistance $800 \Omega$.

Briefly, liquid state cells were grown in $30 \mathrm{~mL}$ TAP culture medium in a $125 \mathrm{~mL}$ Erlenmeyer flask with an initial Optical Density at $750 \mathrm{~nm}\left(\mathrm{OD}_{750 \mathrm{~nm}}\right)$ of $0.1\left(1 \times 10^{5}\right.$ cells $\left./ \mathrm{mL}\right)$ with gentle shaking $(100 \mathrm{rpm})$ to a final $\mathrm{OD}_{750 \mathrm{~nm}}$ of $0.7\left(7 \times 10^{6} \mathrm{cells} / \mathrm{mL}\right)$. Cells were harvested by centrifugation at $7000 \times \mathrm{g}$ for $5 \mathrm{~min}$ and then washed three times by resuspending the pellet in $5 \mathrm{~mL}$ of Max Efficiency ${ }^{\mathrm{TM}}$ Transformation Reagent for Algae (Invitrogen Cat no\# A24229) and centrifuged in the same conditions as in the harvesting step. The samples were incubated on ice for $10 \mathrm{~min}$ prior to electroporation which was performed by applying an electric pulse using $250 \mu \mathrm{L}$ of $C$. reinhardtii cells and $500 \mathrm{ng}$ of linearized purified plasmid. Transgenic strains were resuspended in $5 \mathrm{~mL}$ of TAP liquid medium supplemented with $40 \mathrm{mM}$ sucrose (TAP/sucrose) and then incubated at $25^{\circ} \mathrm{C}$ with gentle shaking (100 rpm) for $22 \mathrm{~h}$ under continuous light. After incubation, the transformed cells were harvested by centrifugation at $7000 \times g$ for $5 \mathrm{~min}$ and resuspended in $250 \mu \mathrm{L}$ of Max Efficiency. Then, spread on TAP agar media supplemented with Hygromycin $(10 \mu \mathrm{g} / \mathrm{mL})$ and incubated in a growth chamber for around 5 to 7 days.

When single clones appeared on agar Petri dish, total number of transformants on each plate was counted using OpenCFU software [38] to determine transformation efficiency.

\subsection{Strains Layout and Selection Method}

Hygromycin-resistant isolated transformants were selected randomly and colonies were sub-cultured on TAP agar plate media supplemented with Hygromycin (Hyg) freshly prepared to verify and ensure their growth stability.

In order to achieve a high throughput screening by CPCR, we have optimized the layout of the clones on the culture media according to the model of a 96-well plate which constitutes the template used for this work as shown in Figure 1. The current approach allows to randomly select the maximum number of clones and to easily maintain them by successive sub-culturing on TAP media supplemented with Hygromycin (hyg). 


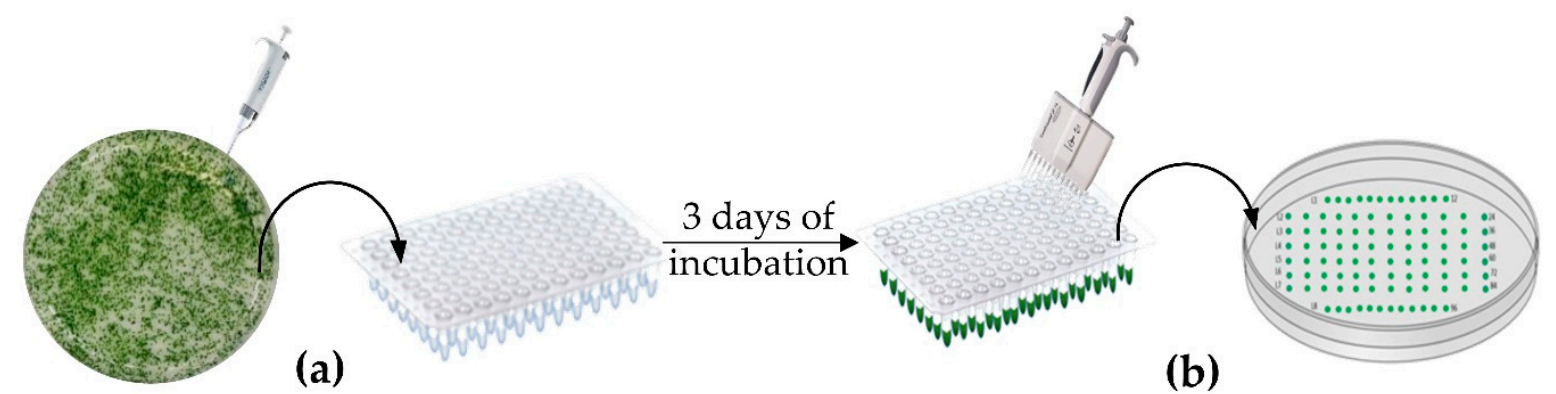

Figure 1. First round of selection and maintenance of transformants. (a) Selection of isolated transformants from tris-acetate phosphate (TAP) agar plate using $10 \mu \mathrm{L}$ tips after 7 days of incubation and inoculation in liquid media in 96-well plate, (b) Sub-culturing and maintaining of selected clones according to the model template of the 96-well plate.

The first selection step was done by picking-up the isolated clones from the transformed C. reinhardtii cells using sterile micropipette tips, and resuspending them in $200 \mu \mathrm{L}$ of TAP containing $10 \mu \mathrm{g} / \mathrm{mL}$ of Hyg liquid medium initially distributed in a cover sterile 96-well plate (Thermofisher Cat no\# 655180) (Figure 1a). Cells in suspension were incubated in the growth chamber under gentle shaking for 3 days. After incubation, $2 \mu \mathrm{L}$ of the suspended cells were withdrawn using a 12-multi-channel micropipette and added, in the same schema as in the 96-well plate, to TAP agar media containing $10 \mu \mathrm{g} / \mathrm{mL}$ of Hyg prepared in a large Petri dish $(150 \mathrm{~mm} \times 15 \mathrm{~mm})$ (Fisher Scientific Cat no\# 249964) (Figure 1b) and incubated for 7 days at $25{ }^{\circ} \mathrm{C}$ under same conditions described in Section 2.2. The selected clones were maintained by several round of subculturing using the same approach as described previously with a 12-multi-channels micropipette every 3 to 4 weeks. Multiple rounds of screening with antibiotics helped to eliminate false positive and verify the stability of the transgene over time.

\subsection{High Throughput Genomic DNA Extraction}

Genomic DNA extraction was done according to the protocol described by Cao et al. [31] with slight modifications. For a better handling of the high number of clones obtained after the transformation and subculture of hygromycin-resistant colonies, we developed a high-throughput DNA extraction procedure. For this, we used the big Petri dishes $(150 \mathrm{~mm} \times 15 \mathrm{~mm}$ ) (Fisher Scientific Cat no\# 249964, Waltham, MA, USA) containing 96 recombinant colonies, laid out for 96-well plate (as shown in Figure 1) and for a 12 multi-channels micropipette (P200). This technique helps to save time by extracting genomic DNA from 96 different clones at the same time (counting the untransformed wild-type as a negative control) (Figure 2).

First, $5 \mathrm{~mL}$ of $5 \%$ Chelex-100 solution was prepared as described by [31] and a volume of $50 \mu \mathrm{L}$ was dispensed, as shown in Figure 2a, in each well of PCR 96 well plate using 12-multi-channels micropipette (or dispensing pipette). Then, with the extremity of the 12-multi-channels micropipette's tips, cells were transferred by tip-touching the clones (around $1 \mathrm{~mm}$ in diameter) from the initial agar plate, and resuspended in the first row of the 96-well plate containing $50 \mu \mathrm{L}$ of $5 \%$ Chelex-100 as described in Figure $2 \mathrm{~b}$. This step is repeated for each row (i.e., 8 times from line A to line $\mathrm{H}$ of the 96-wells plate) following the order on the agar plate and then close the 96-wells plate with an appropriate seal (Thermofisher Scientific Cat no\# AB-0558). The mixture was vigourously vortexed for $10 \mathrm{~s}$ and incubated at $95^{\circ} \mathrm{C}$ (in the PCR thermocycler) for $10 \mathrm{~min}$ (Figure 2c). After incubation, the plate was cool down on ice for $1 \mathrm{~min}$ and vortexed again for $10 \mathrm{~s}$. Finally, the 96-well plate containing the extracted DNA was centrifugated at $3500 \times \mathrm{g}$ for $5 \mathrm{~min}$ at room temperature using a 96-wells plate centrifuge as described in Figure 2c. A volume of $2 \mu \mathrm{L}$ of supernatant of each well was used as DNA samples for PCR reaction (final volume of $25 \mu \mathrm{L}$ ). The concentration of the extracted genomic DNA of the different $C$. reinhardtii transformants were measured using a plate reader (Biotek synergy ${ }^{\mathrm{H} 1}$ 
microplate reader) at $\mathrm{OD}_{260 \mathrm{~nm}}$ (Appendix A Table A1) and DNA samples were stored at $-20^{\circ} \mathrm{C}$ for further use.

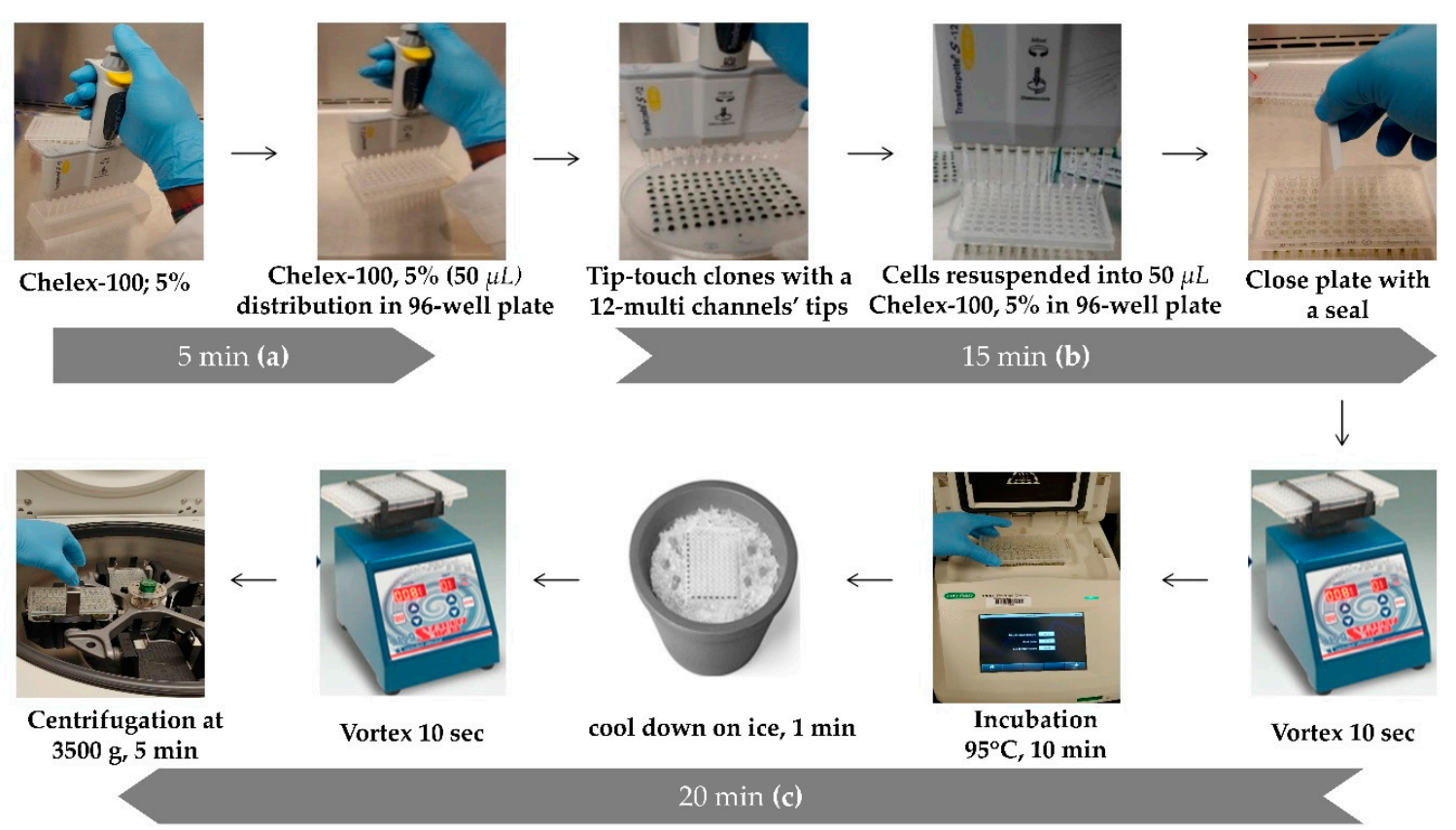

Figure 2. High throughput DNA extraction and time correlation for each step. The protocol is represented in 3 steps corresponding to the first $5 \mathrm{~min}(\mathbf{a})$, followed by the next $15 \mathrm{~min}(\mathbf{b})$ and onto the last $20 \mathrm{~min}(\mathbf{c})$.

\subsection{HT PCR and HT Sample Loading onto Adapted Agarose Gel}

The PCR reaction preparation has been performed using DNA Taq polymerase (New England Biolabs, Whitby, ON, Canada, cat no\# M0273) with the standard thermopol buffer. Reaction mix ( $25 \mu \mathrm{L} / \mathrm{PCR})$, total volume required to assay 96 clones in the same PCR cycle $(2.4 \mathrm{~mL})$, was prepared according to NEB builder's protocol with slight modification (Appendix A Table A2). Once prepared, the mix was poured into a sterile reservoir and a volume of $23 \mu \mathrm{L}$ of reaction mix was aliquoted using a 12-multi-channels micropipette into a 96-well PCR plate (Figure 3a) and $2 \mu \mathrm{L}$ of DNA sample of different $C$. reinhardtii transformants were added into each well (Figure $3 b$ ). The plate was sealed (Thermofisher Scientific Cat no\# AB-0558) to avoid evaporation and then placed into a thermocycler with a specific running cycle to amplify the GOI. The reaction conditions were $95^{\circ} \mathrm{C}$ for $5 \mathrm{~min}$, followed by 34 cycles of denaturation at $95^{\circ} \mathrm{C}$ for $30 \mathrm{~s}$, annealing at $54^{\circ} \mathrm{C}$ for $30 \mathrm{~s}$ and extension $68^{\circ} \mathrm{C}$ for $1 \mathrm{~min}$. The last step of the reaction was a final elongation at $68^{\circ} \mathrm{C}$ for $5 \mathrm{~min}$ and stored at $4^{\circ} \mathrm{C}$.

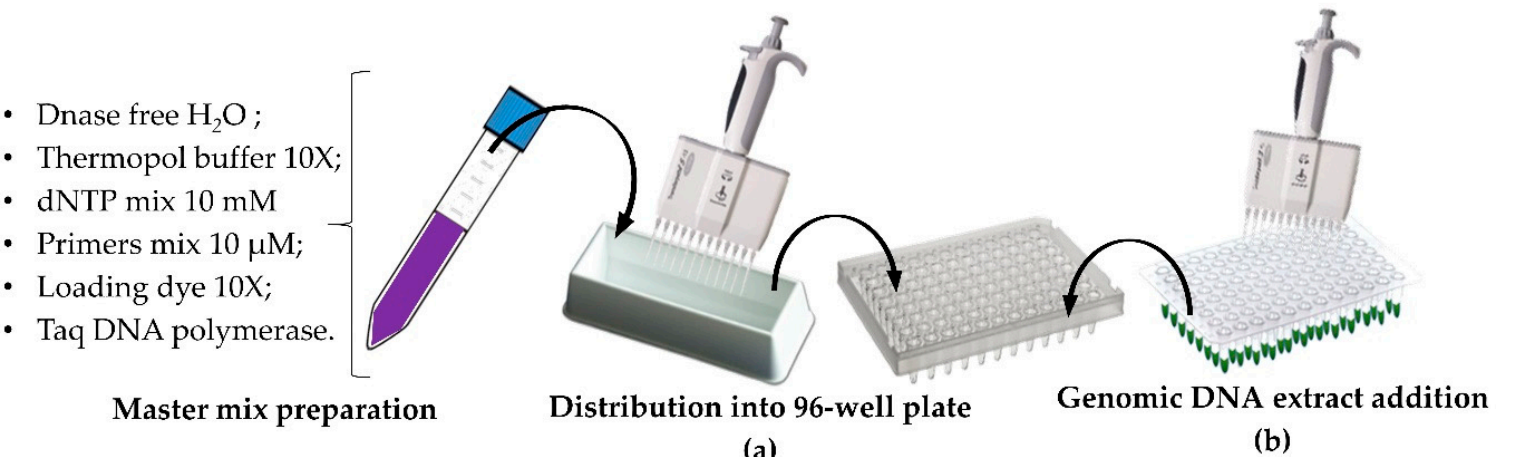

Figure 3. PCR reaction mix preparation and aliquoting. (a) master mix reaction preparation and distribution into 96-well plate; (b) DNA sample addition in the PCR reaction mix. 
In order to be able to easily load all the amplification products on an agarose gel, two large electrophoretic tanks containing an adapted 52 wells comb were used. The loading dye buffer 10X was prepared with bromophenol blue and glycerol as described by Le Gouill and al., [39] with slight modifications. It was initially added directly into the PCR reaction mix (as shown in Figure 3) before the amplification step so that the PCR amplified samples were loaded directly onto the $1 \%$ agarose gel using a 12-multi-channels micropipette.

This experimental step allowed us either to highlight and confirm the HTS genomic DNA (gDNA) extraction protocol by amplifying a $944 \mathrm{bp}$ fragment of the genomic DNA of Chlamydomonas that is specific to the PGK gene (as reference gene and positive control of the genomic DNA extraction), or to select the positive clones during the screening experiment by HTS-cPCR. Both primer pairs (for PGK and GOI) were used in the same PCR reaction. Positive transformants were identified by amplifying a $506 \mathrm{bp}$ fragment of the gene of interest GOI. This method allows to screen rapidly and select a high number of genetically transformed C. reinhardtii microalgae.

\section{Results}

\subsection{Strains Layout and HTS DNA Extraction}

A high transformation efficiency of up to $1 \times 10^{6} \mathrm{CFU} / \mu \mathrm{g}$ of linear plasmid DNA was obtained using the electroporation method. After 5 to 7 days of incubation on TAP agar plate supplemented with $10 \mu \mathrm{g} / \mathrm{mL}$ of hygromycin, we obtained more than 7000 C. reinhardtii transformants (Figure 4a). A total of 1440 transformants were selected randomly and cultured according to the layout on TAP agar following a 96-well plate model (Figure $4 \mathrm{~b}$ ). The use of the 96-well format template is modern state of art for different Chlamydomonas laboratories and it facilitates a better management of high numbers of clones. This layout of transformants on the TAP agar media allows for the rapid round culturing of the clones and for the easy pick-up of colonies for the high throughput genomic DNA extraction.

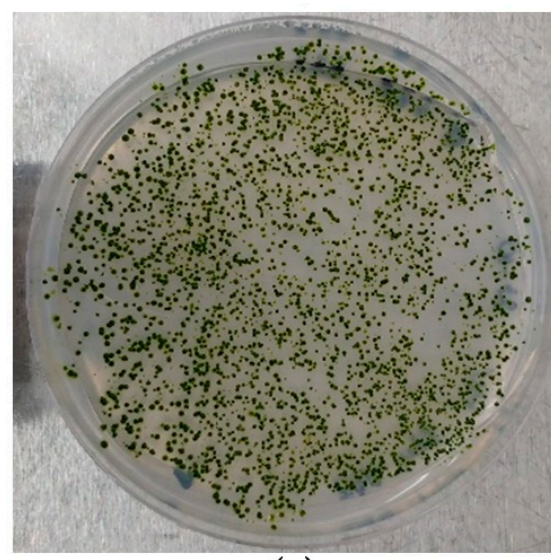

(a)

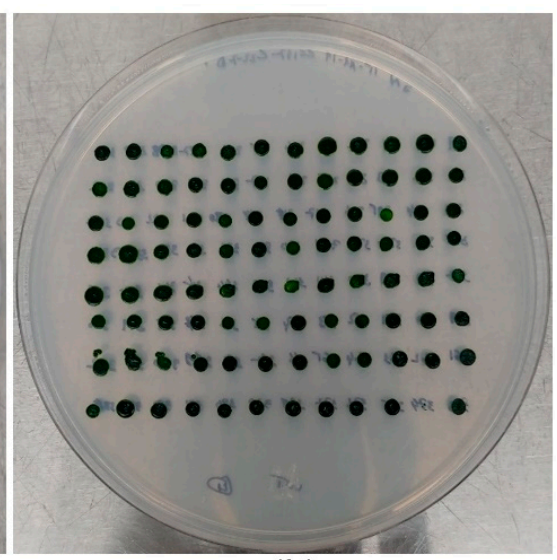

(b)

Figure 4. Antibiotic selective TAP agar plate containing genetically transformed C. reinhardtii. (a) Colonies obtained after 7 days incubation of genetically transformed cells; (b) transformants layout as 96-well plate on culture medium.

After the high throughput extraction, the genomic DNA concentration was measured using the Take three plate into the plate reader (Biotek synergy ${ }^{\mathrm{H} 1}$ microplate reader) (Appendix A Table A1). This assay was performed to ensure that the DNA concentration obtained following our high throughput DNA extraction was relatively uniformed across all colony tested and within each cPCR reaction and that the DNA quality was good [40].

The range of DNA concentration of the transformants was between 21 to $317 \mathrm{ng} / \mu \mathrm{L}$ and showed high purity according to the OD ratio 260/280 nm (Appendix A Table A1) [41]. Genomic DNA extraction 
can also be performed from liquid cell cultures from the 96-well plate after 3 days incubation in selective media (Figure 1a) for cPCR amplification (data not shown).

\subsection{High-Troughput Screening cPCR and Revelation}

Genomic DNA samples from 1440 transgenic C. reinhardtii and wild type were extracted using HTS extraction method as described in the materials and methods section. The nuclear PGK gene was used as reference to check the quality, reliability, and specificity of extracted genomic DNA. A fragment of $944 \mathrm{bp}$ of the PGK gene was amplified to provide an example from 48 C. reinhardtii transformed and untransformed (named here $\mathrm{wt}$ ) clones (Figure 5). The result showed the efficiency of HT genomic DNA extraction and HT amplification method. Forty-eight positive amplicons of PGK gene were obtained out of $48 \mathrm{cPCR}$. Thus, the specific high throughput screening and selection of mutants positively transformed becomes easier using the specific primers in the same reactional mix for the amplification of the gene of interest in the same genomic DNA samples. In addition, DNA extracted sample can be used for PCR amplification after storage at $-20^{\circ} \mathrm{C}$.

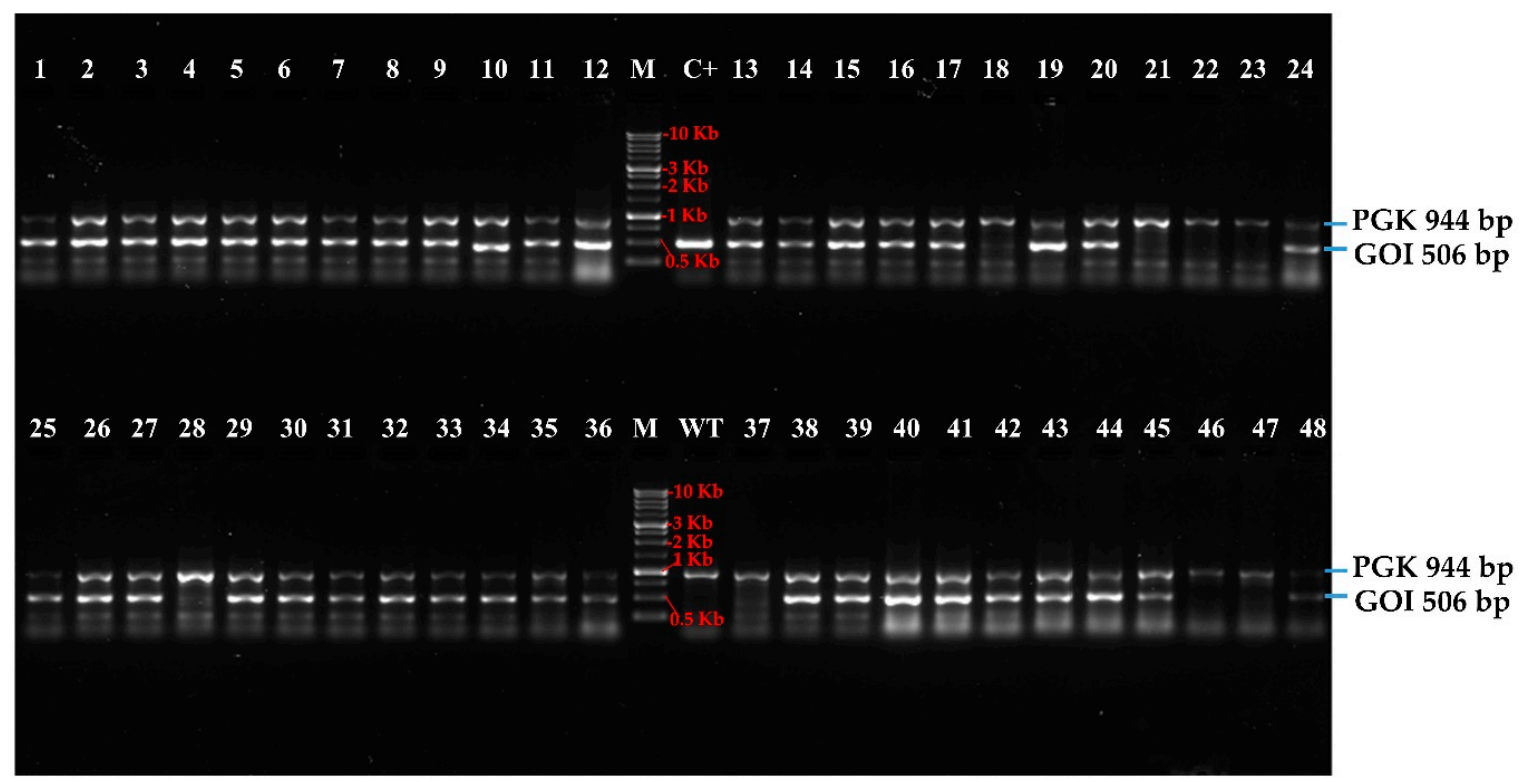

Figure 5. Example of stained SYBR safe agarose gel (1\%) showed amplicon of 48 samples: (PGK) 48 nuclear phosphoglycerate kinase (PGK) gene PCR amplification at 944 bp; (GOI) 48 gene of interest (GOI) PCR amplification at $506 \mathrm{bp}$. PCR samples were migrated at $100 \mathrm{volt} / \mathrm{cm}$ for $60 \mathrm{~min}$. Colony numbers are shown on top of the wells M: 1kb DNA ladder, Froggabio Cat. DM010-R500; wt: wild type (untransformed C. reinhardtii) extracted using the same standard protocol as the transformed clones; $\mathrm{C}+$ : positive control is plasmid construct (pOpt_mRuby_Hyg-GOI).

In the same order, the amplification of a fragment of $506 \mathrm{bp}$ related to the GOI from 48 transformed clones showed 40 positive clones (Figure 5). The number of PCR-positive transformants/number of transformants analyzed ratio is $646 / 1336$. Thus, the percentage of positive colonies is $48.3 \%$ (Table 1 ).

Table 1. Number of transgenes selected by the high-throughput screening (HTS)-screening method.

\begin{tabular}{cccc}
\hline $\begin{array}{c}\text { Number of Colonies } \\
\text { Counted After } \\
\text { Electroporation }\end{array}$ & $\begin{array}{c}\text { Number of Clones } \\
\text { Selected Randomly }\end{array}$ & $\begin{array}{c}\text { Viable Clones After Six } \\
\text { Round Sub-Culturing } \\
\text { (\% of Viable Cells) }\end{array}$ & $\begin{array}{c}\text { Positive Clones After } \\
\text { HTS-Colony-PCR (\% of } \\
\text { Positive Colonies) }\end{array}$ \\
\hline 7000 & 1440 & $1336(93)$ & $646(48,3)$ \\
\hline
\end{tabular}

By using this HTS-screening method, we were able to obtain 646 positive transformants over 1336 viable transformants selected after transformation (Table 1). 


\section{Discussion}

According to Cao et al., [31], colony-PCR (or cPCR) is known as a highly efficient method of genetic detection. This standard gold technique also has diverse advantages for the screening and selection of genetically transformed cells. Regarding microalgae transformation, this method is shown to be efficient and more specific for the screening and selection of positive transgenes in several genetically transformed green algae such as C. reinhardtii, Chlorella pyrenoidosa to name a few [42-46].

The transformation of $C$. reinhardtii using the electroporation method led to a high number of transformants with a transformation efficiency of $1 \times 10^{6} \mathrm{CFU} / \mathrm{\mu g}$ of linear plasmid DNA [37]. Because of the random integration of a transgene into the $C$. reinhardtii nuclear genome, the fact that transformants can grow on TAP agar supplemented with hygromycin does not necessarily imply that the clones also integrated the gene of interest. Thus, it is very important to screen a high number of clones to increase the chances of selecting transformants which could have integrated one or multiple copies of the exogenous gene of interest and feature high transgene expression [14].

In order to tackle this issue, we optimized a high throughput screening (HTS) method based on our standard cPCR protocol. In this study, we showed that this HTS screening/selection method is easier, more practical and efficient to test and manage a high number of transformants either for $\mathrm{CPCR}$ assay, loading samples (onto agarose gel) or culture maintenance of transformants. Our developed method was compared to the standard screening (STS) method based on individual selection and maintenance, DNA extraction and PCR of transformants clone by clone. This HTS method is not only fast and efficient, but also less expensive and requires less working-time, unlike the STS method, which is more laborious. In Table 2, we present the working-time comparison determined between the STS method and HTS method on 96 clones by CPCR during this study. This comparison was done mainly for the principal steps of the experiment.

Table 2. Working-time comparison between standard screening (STS; 96 colonies) and high throughput screening (HTS; 96 colonies) cPCR method.

\begin{tabular}{cccc}
\hline \multirow{2}{*}{ Steps } & STS & HTS & Difference \\
\cline { 2 - 4 } & \multicolumn{3}{c}{ Time (min) } \\
\hline DNA extraction & 360 & 40 & 320 \\
Mix PCR preparation and distribution & 150 & 35 & 115 \\
Gel preparation and sample loading & 150 & 20 & 130 \\
\hline Total & 660 & 95 & 565 \\
\hline
\end{tabular}

The standard cPCR method is clearly a highly time-consuming step when the number of clones tested is elevated to hundreds (for example 96 clones). The HTS-PCR is a six-fold time-saving method which makes work less laborious and cheaper in terms of time, material or money. Moreover, using this method allowed us to avoid mistakes that can occur while working with single tube, and increase the reliability of the result as well as positive clones selected. Indeed, the percentage of positive colonies obtained using HTS was $48.3 \%$, compared to the $20 \%$ using conventional screening. Besides all the advantages given by this method, it is important to note that the HTS-PCR is reflected positively in the ecological plan due to reduction of consumable and material used that could be a threat for the environment (such as single Eppendorf tubes and single PCR tubes to 96 wells plates i.e., less plastics). Finally, the layout template and the use of multi-channels pipets for culturing and maintaining the positive clones could be a useful technique for any genetic screening tool such as Southern blotting.

\section{Conclusions}

In this work, we described the high throughput screening of $C$. reinhardtii genetically transformed cells and established a promising, reliable and rapid routine colony-PCR (cPCR) technique. This could help for easier and enhanced screening and selection of massive number of positive transformed cells, 
which could serve for academic and industrial uses. This technique also allows the manipulation of a high number of positively transformed cells accurately. In addition, more errors can be introduced from the standard technique which becomes very laborious and requires a lot of working-time when the number of clones to be tested becomes large.

In further studies, we aim to implement the HTS detection system for gene expression, based on the use of fluorescent proteins. We hope that this fast model HTS system could facilitate the first step of selecting the supposedly positive clones directly on agar plate before proceeding by any further analysis.

Author Contributions: Conceptualization, S.B.N., M.G., F.M., H.G. and I.D.-P.; Methodology, S.B.N., M.G., R.B. and F.M.-M.; Validation, S.B.N., M.G., R.B. and F.M.-M.; Formal analysis, S.B.N. and M.G.; Investigation, S.B.N. and M.G.; Writing-original draft preparation, S.B.N., M.G. and F.M.-M.; Writing-review and editing, S.B.N., M.G., R.B., F.M.-M., H.G. and I.D.-P.; Supervision, H.G. and I.D.-P.; Project administration, I.D.-P.; Funding acquisition, I.D.-P. All authors have read and agreed to the published version of the manuscript.

Funding: This work was funded by the Natural Sciences and Engineering Research Council of Canada-Collaborative Research and Development grant reference no CRDPJ/530085-18 to IDP. Students (S.B.N. and R.B.) and postdoctoral fellow (M.G.) are supported by Mitacs-Acceleration program grants no IT12310 and IT13619 to IDP.

Acknowledgments: The authors wish to thank the industrial collaborator Mather Carscallen and Algae-C for sample and support.

Conflicts of Interest: The authors declare no conflict of interest.

\section{Appendix A}

Our study used the following vector (Figure A1).

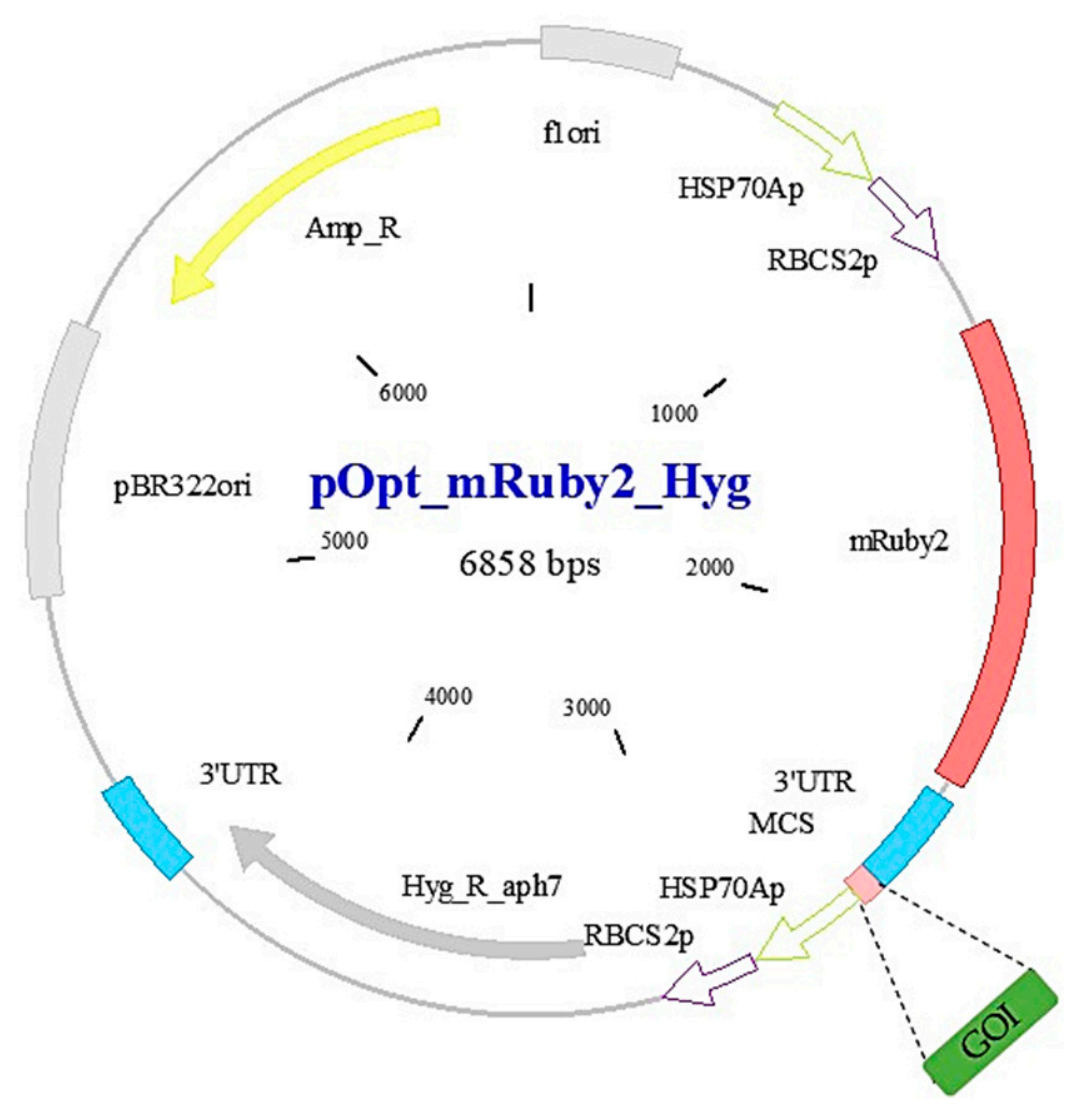

Figure A1. Vector map of the recombinant pOpt_mRuby2_Hyg vector [21] containing gene of interest (GOI). The vector map was made using Clone Manager suite 7 software. 


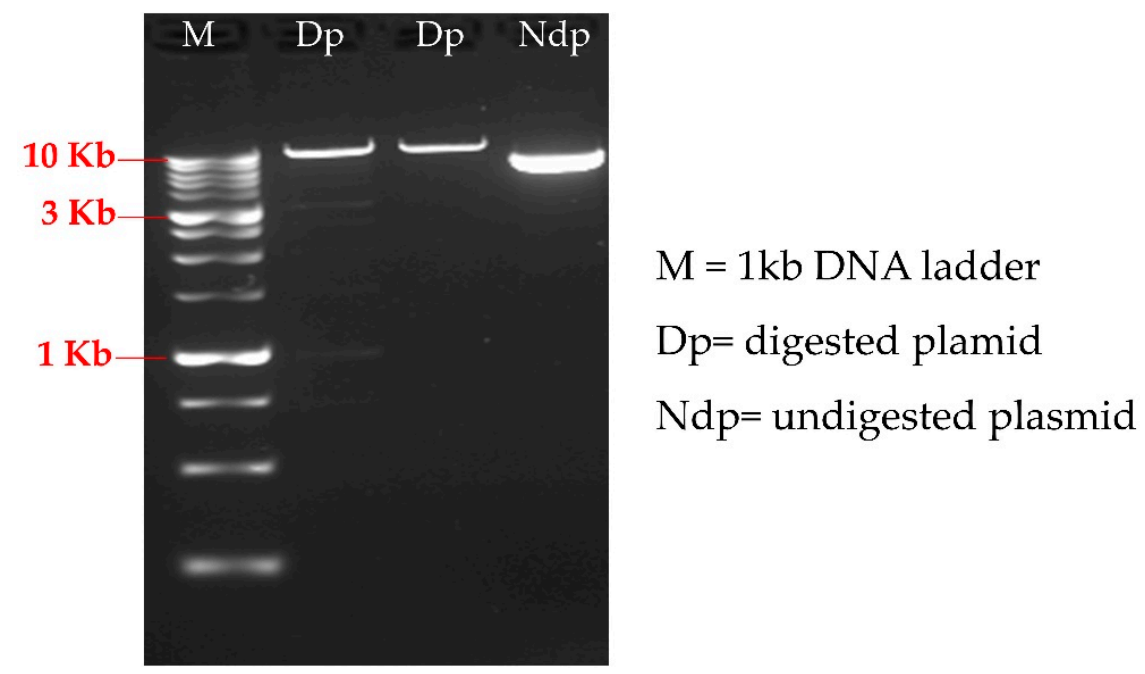

Figure A2. Linearization of the plasmid pOpt_mRuby2_Hyg containing gene of interest using the restriction enzyme ScaI. The $1 \mathrm{~kb}$ DNA ladder used is from FroggaBio (Concord, ON, Canada) Cat. DM010-R500

The results for the DNA concentration are displayed in Table A1.

Table A1. Genomic DNA concentration obtained after HT DNA extraction in 96-well plate. Here we show 48 DNA extracted samples.

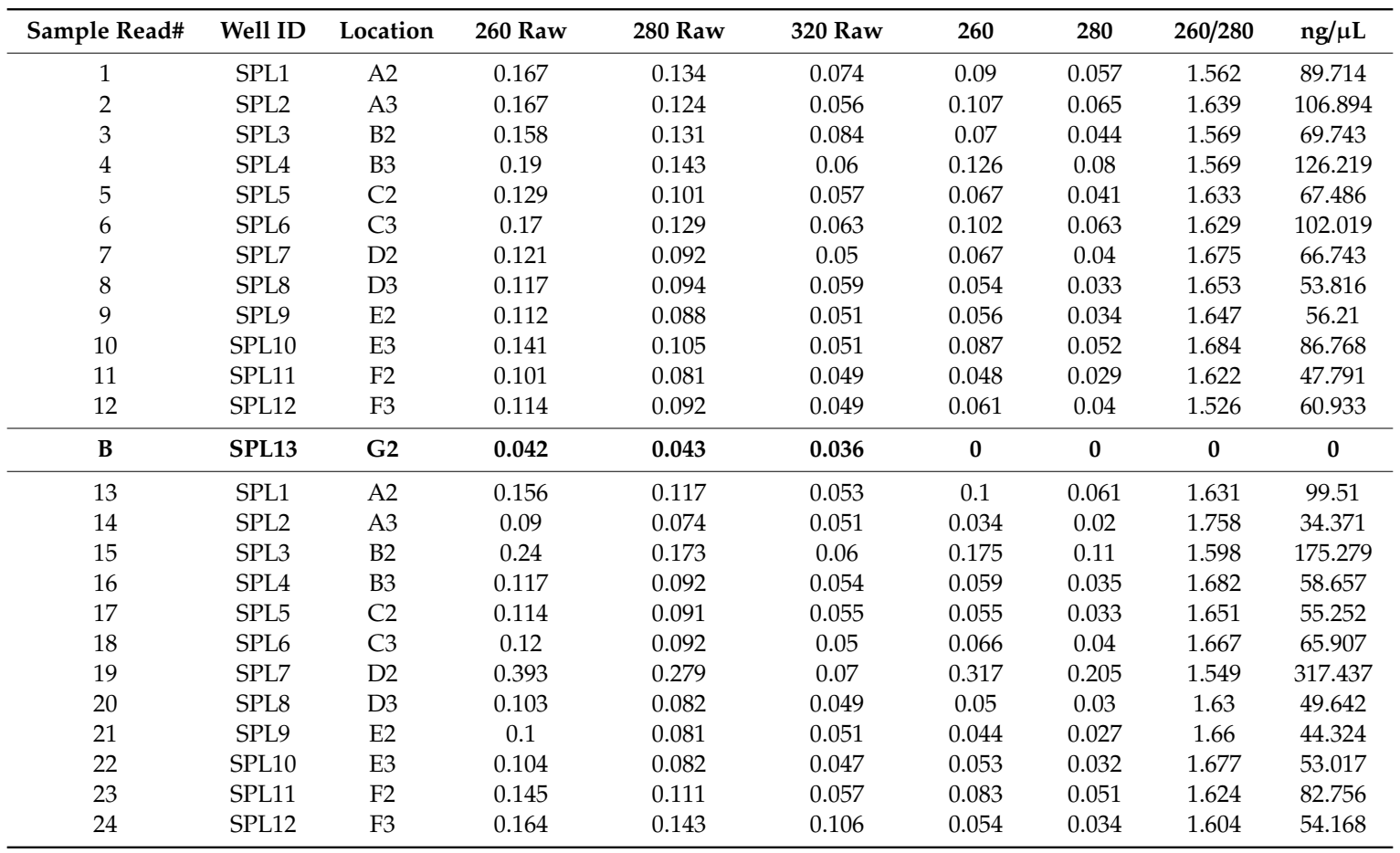


Table A1. Cont.

\begin{tabular}{|c|c|c|c|c|c|c|c|c|c|}
\hline Sample Read\# & Well ID & Location & 260 Raw & 280 Raw & 320 Raw & 260 & 280 & $260 / 280$ & $\mathrm{ng} / \mu \mathrm{L}$ \\
\hline B & SPL13 & G2 & 0.045 & 0.042 & 0.039 & 0 & 0 & 0 & 0 \\
\hline 25 & SPL1 & A2 & 0.118 & 0.093 & 0.049 & 0.066 & 0.041 & 1.593 & 65.524 \\
\hline 27 & SPL3 & B2 & 0.174 & 0.126 & 0.05 & 0.12 & 0.074 & 1.63 & 119.823 \\
\hline 28 & SPL4 & B3 & 0.259 & 0.191 & 0.068 & 0.186 & 0.119 & 1.562 & 186.418 \\
\hline 29 & SPL5 & $\mathrm{C} 2$ & 0.233 & 0.169 & 0.054 & 0.174 & 0.111 & 1.566 & 174.01 \\
\hline 32 & SPL8 & D3 & 0.114 & 0.09 & 0.055 & 0.055 & 0.033 & 1.672 & 54.91 \\
\hline 33 & SPL9 & E2 & 0.072 & 0.061 & 0.044 & 0.024 & 0.014 & 1.723 & 24.317 \\
\hline 34 & SPL10 & E3 & 0.083 & 0.067 & 0.044 & 0.034 & 0.02 & 1.689 & 34.399 \\
\hline 35 & SPL11 & $\mathrm{F} 2$ & 0.145 & 0.114 & 0.065 & 0.076 & 0.046 & 1.637 & 75.822 \\
\hline 36 & SPL12 & F3 & 0.105 & 0.084 & 0.049 & 0.053 & 0.033 & 1.618 & 52.875 \\
\hline 39 & SPL3 & B2 & 0.15 & 0.114 & 0.051 & 0.095 & 0.06 & 1.577 & 95.231 \\
\hline 40 & SPL4 & B3 & 0.354 & 0.259 & 0.064 & 0.286 & 0.192 & 1.49 & 285.522 \\
\hline 41 & SPL5 & $\mathrm{C} 2$ & 0.216 & 0.163 & 0.061 & 0.151 & 0.098 & 1.532 & 150.736 \\
\hline 42 & SPL6 & C3 & 0.113 & 0.088 & 0.045 & 0.064 & 0.04 & 1.602 & 64.316 \\
\hline 43 & SPL7 & D2 & 0.206 & 0.155 & 0.057 & 0.145 & 0.096 & 1.517 & 144.948 \\
\hline 44 & SPL8 & D3 & 0.327 & 0.241 & 0.074 & 0.248 & 0.164 & 1.514 & 247.814 \\
\hline 45 & SPL9 & E2 & 0.177 & 0.135 & 0.058 & 0.114 & 0.074 & 1.547 & 113.956 \\
\hline 46 & SPL10 & E3 & 0.154 & 0.118 & 0.051 & 0.099 & 0.065 & 1.53 & 98.815 \\
\hline 47 & SPL11 & $\mathrm{F} 2$ & 0.381 & 0.282 & 0.097 & 0.277 & 0.18 & 1.538 & 276.991 \\
\hline 48 & SPL12 & F3 & 0.157 & 0.118 & 0.052 & 0.101 & 0.063 & 1.609 & 100.925 \\
\hline
\end{tabular}

$\mathrm{B}=$ The bold raw represent blank negative control (distilled water).

Our study used the following master mix preparation (Table A2).

Table A2. Reaction master mix preparation (source NEB builder [47]).

\begin{tabular}{ccc}
\hline Component & $\mathbf{2 5} \mu \mathrm{L}$ Reaction & Final Concentration \\
\hline $10 \times$ ThermoPol Reaction Buffer & $2.5 \mu \mathrm{L}$ & $1 \mathrm{X}$ \\
\hline $10 \mathrm{mM}$ dNTPs & $0.5 \mu \mathrm{L}$ & $200 \mu \mathrm{M}$ \\
\hline $10 \mu \mathrm{M}$ Forward Primer mix (PGK/GOI) & $0.5 \mu \mathrm{L}$ & $0.2 \mu \mathrm{M}(0.05-1 \mu \mathrm{M})$ \\
\hline $10 \mu \mathrm{M}$ Reverse Primer mix (PGK/GOI) & $0.5 \mu \mathrm{L}$ & $0.2 \mu \mathrm{M}(0.05-1 \mu \mathrm{M})$ \\
\hline $10 \times$ Loading Dye Buffer & $1 \mu \mathrm{L}$ & $0.4 \mathrm{X}$ \\
\hline Template DNA & $2 \mu \mathrm{L}$ & $<1000 \mathrm{ng}$ \\
\hline Taq DNA Polymerase & $0.125 \mu \mathrm{L}$ & 1.25 units/50 $\mu \mathrm{L}$ PCR \\
\hline Nuclease-free water & To $25 \mu \mathrm{L}$ & \\
\hline
\end{tabular}

\section{References}

1. Malcata, F.X.; Pinto, I.S.; Guedes, A.C. Marine Macro-and Microalgae: An Overview; CRC Press: Boca Raton, FL, USA, 2018.

2. Salomé, P.A.; Merchant, S.S. A Series of Fortunate Events: Introducing Chlamydomonas as a Reference Organism. Plant Cell 2019, 31, 1682-1707. [CrossRef] [PubMed]

3. Merchant, S.S.; Prochnik, S.E.; Vallon, O.; Harris, E.H.; Karpowicz, S.J.; Witman, G.B.; Terry, A.; Salamov, A.; Fritz-Laylin, L.K.; Maréchal-Drouard, L.; et al. The Chlamydomonas Genome Reveals the Evolution of Key Animal and Plant Functions. Science 2007, 318, 245-250. [CrossRef] [PubMed]

4. Scranton, M.A.; Ostrand, J.T.; Fields, F.J.; Mayfield, S.P. Chlamydomonas as a model for biofuels and bio-products production. Plant J. 2015, 82, 523-531. [CrossRef] 
5. Scaife, M.A.; Nguyen, G.T.; Rico, J.; Lambert, D.; Helliwell, K.E.; Smith, A.G. Establishing Chlamydomonas reinhardtii as an industrial biotechnology host. Plant J. 2015, 82, 532-546. [CrossRef]

6. Kong, F.; Yamaoka, Y.; Ohama, T.; Lee, Y.; Li-Beisson, Y. Molecular Genetic Tools and Emerging Synthetic Biology Strategies to Increase Cellular Oil Content in Chlamydomonas reinhardtii. Plant Cell Physiol. 2019, 60, 1184-1196. [CrossRef] [PubMed]

7. Leon, R. Transgenic microalgae as green cell-factories. Trends Biotechnol. 2004, 22, 45-52. [CrossRef]

8. Leon, R.; Fernandez, E. Nuclear transformation of eukaryotic microalgae. In Transgenic Microalgae as Green Cell Factories; Springer: Berlin/Heidelberg, Germany, 2007; pp. 1-11.

9. Kindle, K.L. High-frequency nuclear transformation of Chlamydomonas reinhardtii. Proc. Natl. Acad. Sci. USA 1990, 87, 1228-1232. [CrossRef]

10. Shimogawara, K.; Fujiwara, S.; Grossman, A.; Usuda, H. High-efficiency transformation of Chlamydomonas reinhardtii by electroporation. GenetICS 1998, 148, 1821-1828.

11. Kumar, S.V.; Misquitta, R.W.; Reddy, V.S.; Rao, B.J.; Rajam, M.V. Genetic transformation of the green alga-Chlamydomonas reinhardtii by Agrobacterium tumefaciens. Plant Sci. 2004, 166, 731-738. [CrossRef]

12. Zhang, Y.; Yan, Y.-P.; Wu, Y.-C.; Hua, W.; Chen, C.; Ge, Q.; Wang, Z.-Z. Pathway engineering for phenolic acid accumulations in Salvia miltiorrhiza by combinational genetic manipulation. Metab. Eng. 2014, 21, 71-80. [CrossRef]

13. Jinkerson, R.E.; Jonikas, M.C. Molecular techniques to interrogate and edit the Chlamydomonas nuclear genome. Plant J. 2015, 82, 393-412. [CrossRef] [PubMed]

14. Nour-Eldin, H.H.; Specht, E.A.; Ostrand, J.; Hoang, K.T.; Karunanithi, P.S.; Mayfield, S.P. High-throughput system for quantifying and characterizing homologous recombination in Chlamydomonas reinhardtii. Algal Res. 2018, 31, 167-172. [CrossRef]

15. Yamano, T.; Iguchi, H.; Fukuzawa, H. Rapid transformation of Chlamydomonas reinhardtii without cell-wall removal. J. Biosci. Bioeng. 2013, 115, 691-694. [CrossRef] [PubMed]

16. Shahar, N.; Landman, S.; Weiner, I.; Elman, T.; Dafni, E.; Feldman, Y.; Tuller, T.; Yacoby, I. The Integration of Multiple Nuclear-Encoded Transgenes in the Green Alga Chlamydomonas reinhardtii Results in Higher Transcription Levels. Front. Plant Sci. 2020, 10. [CrossRef] [PubMed]

17. Weiner, I.; Atar, S.; Schweitzer, S.; Eilenberg, H.; Feldman, Y.; Avitan, M.; Blau, M.; Danon, A.; Tuller, T.; Yacoby, I. Enhancing heterologous expression in Chlamydomonas reinhardtii by transcript sequence optimization. Plant J. 2018, 94, 22-31. [CrossRef]

18. Mussgnug, J.H. Nuclear Transformation and Toolbox Development. In Chlamydomonas: Molecular Genetics and Physiology; Springer: Berlin/Heidelberg, Germany, 2017; pp. 27-58.

19. Rasala, B.A.; Lee, P.A.; Shen, Z.; Briggs, S.P.; Mendez, M.; Mayfield, S.P. Robust Expression and Secretion of Xylanase1 in Chlamydomonas reinhardtii by Fusion to a Selection Gene and Processing with the FMDV 2A Peptide. PLoS ONE 2012, 7, e43349. [CrossRef]

20. Lauersen, K.; Berger, H.; Mussgnug, J.H.; Kruse, O. Efficient recombinant protein production and secretion from nuclear transgenes in Chlamydomonas reinhardtii. J. Biotechnol. 2013, 167, 101-110. [CrossRef]

21. Lauersen, K.; Kruse, O.; Mussgnug, J.H. Targeted expression of nuclear transgenes in Chlamydomonas reinhardtii with a versatile, modular vector toolkit. Appl. Microbiol. Biotechnol. 2015, 99, 3491-3503. [CrossRef]

22. Kong, F.; Yamasaki, T.; Kurniasih, S.D.; Hou, L.; Li, X.; Ivanova, N.; Okada, S.; Ohama, T. Robust expression of heterologous genes by selection marker fusion system in improved Chlamydomonas strains. J. Biosci. Bioeng. 2015, 120, 239-245. [CrossRef]

23. Plucinak, T.M.; Horken, K.M.; Jiang, W.; Fostvedt, J.; Nguyen, S.T.; Weeks, D.P. Improved and versatile viral 2A platforms for dependable and inducible high-level expression of dicistronic nuclear genes in Chlamydomonas reinhardtii. Plant J. 2015, 82, 717-729. [CrossRef]

24. Rasala, B.A.; Mayfield, S.P. Photosynthetic biomanufacturing in green algae; production of recombinant proteins for industrial, nutritional, and medical uses. Photosynth. Res. 2014, 123, 227-239. [CrossRef] [PubMed]

25. Onishi, M.; Pringle, J.R. Robust Transgene Expression from Bicistronic mRNA in the Green Alga Chlamydomonas reinhardtii. G3: Genes Genomes Genet. 2016, 6, 4115-4125. [CrossRef] [PubMed] 
26. Molino, J.V.D.; De Carvalho, J.C.M.; Mayfield, S.P. Comparison of secretory signal peptides for heterologous protein expression in microalgae: Expanding the secretion portfolio for Chlamydomonas reinhardtii. PLoS ONE 2018, 13, e0192433. [CrossRef]

27. Lauersen, K.; Baier, T.; Wichmann, J.; Wördenweber, R.; Mussgnug, J.H.; Hübner, W.; Huser, T.R.; Kruse, O. Efficient phototrophic production of a high-value sesquiterpenoid from the eukaryotic microalga Chlamydomonas reinhardtii. Metab. Eng. 2016, 38, 331-343. [CrossRef] [PubMed]

28. López-Paz, C.; Liu, D.; Geng, S.; Umen, J.G. Identification of Chlamydomonas reinhardtii endogenous genic flanking sequences for improved transgene expression. Plant J. 2017, 92, 1232-1244. [CrossRef]

29. Baier, T.; Wichmann, J.; Kruse, O.; Lauersen, K. Intron-containing algal transgenes mediate efficient recombinant gene expression in the green microalga Chlamydomonas reinhardtii. Nucleic Acids Res. 2018, 46, 6909-6919. [CrossRef]

30. Wichmann, J.; Baier, T.; Wentnagel, E.; Lauersen, K.; Kruse, O. Tailored carbon partitioning for phototrophic production of (E)- $\alpha$-bisabolene from the green microalga Chlamydomonas reinhardtii. Metab. Eng. 2018, 45, 211-222. [CrossRef]

31. Cao, M.; Fu, Y.; Guo, Y.; Pan, J. Chlamydomonas (Chlorophyceae) colony PCR. Protoplasma 2009, 235, 107-110. [CrossRef]

32. Sheu, D.-S.; Wang, Y.-T.; Lee, C.-Y. Rapid detection of polyhydroxyalkanoate-accumulating bacteria isolated from the environment by colony PCR. Microbiology 2000, 146, 2019-2025. [CrossRef]

33. Chlamydomonas Resource Center. Available online: http://chlamycollection.org/ (accessed on 10 September 2020).

34. Liu, C.; Wu, G.; Huang, X.; Liu, S.; Cong, B. Validation of housekeeping genes for gene expression studies in an ice alga Chlamydomonas during freezing acclimation. Extremophiles 2012, 16, 419-425. [CrossRef]

35. Integrated DNA Techonologies. Available online: https://www.idtdna.com/ (accessed on 10 September 2020).

36. Wittkopp, T. Nuclear Transformation of Chlamydomonas reinhardtii by Electroporation. BIO-PROTOCOL 2018, 8. [CrossRef]

37. Wang, L.; Yang, L.; Wen, X.; Chen, Z.; Liang, Q.; Li, J.; Wang, W. Rapid and high efficiency transformation of Chlamydomonas reinhardtii by square-wave electroporation. Biosci. Rep. 2019, 39. [CrossRef]

38. Geissmann, Q. OpenCFU, a New Free and Open-Source Software to Count Cell Colonies and Other Circular Objects. PLoS ONE 2013, 8, e54072. [CrossRef] [PubMed]

39. Le Gouil, C.; Déry, C. A rapid procedure for the screening of recombinant plasmids. Nucleic Acids Res. 1991, 19, 6655. [CrossRef] [PubMed]

40. Song, Y.; Fahs, A.; Feldman, C.; Shah, S.; Gu, Y.; Wang, Y.; Machado, R.F.; Wunderink, R.G.; Chen, J. A reliable and effective method of DNA isolation from old human blood paper cards. SpringerPlus 2013, 2, 1-7. [CrossRef] [PubMed]

41. Chen, Y.; Bi, C.; Tong, S.; Gong, Z.; Hou, H. An improved and reliable method for microalgae direct PCR. Environ. Boil. Fishes 2019, 31, 2411-2421. [CrossRef]

42. Lai, M.-Y.; Abdul-Majid, N.; Lau, Y.-L. Identification of Host Proteins Interacting with Toxoplasma gondii SAG1 by Yeast Two-Hybrid Assay. Acta Parasitol. 2019, 64, 575-581. [CrossRef]

43. Kindo, A.J.; Vijayaraman, R.S.; Ramaraj, V. Direct colony polymerase chain reaction for rapid identification of yeasts isolated from blood specimen. J. Acad. Clin. Microbiol. 2016, 18, 91. [CrossRef]

44. Walch, G.; Knapp, M.; Rainer, G.; Peintner, U. Colony-PCR Is a Rapid Method for DNA Amplification of Hyphomycetes. J. Fungi 2016, 2, 12. [CrossRef]

45. Azevedo, F.; Pereira, H.; Johansson, B. Colony PCR. In PCR.; Springer: Berlin/Heidelberg, Germany, 2017; pp. 129-139.

46. Run, C.; Fang, L.; Fan, J.; Fan, C.-M.; Luo, Y.; Hu, Z.-M.; Li, Y. Stable nuclear transformation of the industrial alga Chlorella pyrenoidosa. Algal Res. 2016, 17, 196-201. [CrossRef]

47. New England Biolabs Inc. Available online: https://international.neb.com/protocols/0001/01/01/taq-dnapolymerase-with-thermopol-buffer-m0267 (accessed on 10 September 2020).

(C) 2020 by the authors. Licensee MDPI, Basel, Switzerland. This article is an open access article distributed under the terms and conditions of the Creative Commons Attribution (CC BY) license (http://creativecommons.org/licenses/by/4.0/). 